\title{
Porous graphitic materials obtained from carbonization of organic xerogels doped with transition metal salts
}

\author{
W KICIŃSKI I,*, M BYSTRZEJEWSKI ${ }^{2}$, M H RÜMMELI ${ }^{3,4}$ and T GEMMING ${ }^{5}$ \\ ${ }^{1}$ Institute of Chemistry, Military University of Technology, Kaliskiego 2, 00-908 Warsaw, Poland \\ ${ }^{2}$ Department of Chemistry, Warsaw University, Pasteur 1, 02-093 Warsaw, Poland \\ ${ }^{3}$ IBS Center for Integrated Nanostructure Physics, Institute for Basic Science (IBS), Daejon 305-701, Republic of Korea \\ ${ }^{4}$ Department of Energy Science, Department of Physics, Sungkyunkwan University, Suwon 440-746, Republic of Korea \\ ${ }^{5}$ IFW Dresden, Helmholtzstr. 20, 01069 Dresden, Germany
}

MS received 20 August 2012; revised 19 December 2012

\begin{abstract}
Porous carbons with a well developed graphitic phase were obtained via the pyrolysis of $\mathrm{FeCl}_{3}-, \mathrm{NiCl}_{2}-$, and $\mathrm{CoCl}_{2}$-doped organic xerogels. Doping was realized through salt solubilization in a water/methanol solution of resorcinol and furfural. Carbon xerogels with tailored particles, porous morphology and various degrees of graphitization were obtained depending of the water/methanol ratio and the salt content and type in the starting solution of substrates. When obtained via pyrolysis, carbon xerogels retain the overall open-celled structure exhibiting depleted microporosity and a well-developed mesoporic region that expands into macropores. The removal of metal leads to carbon xerogels with specific surface areas between 170 and $585 \mathrm{~m}^{2} / \mathrm{g}$ and pore volume up to $0 \cdot 76 \mathrm{~cm}^{3} / \mathrm{g}$. The possibility of enhancing the porosity of xerogels via templating with colloidal silica was also investigated. It was assumed that from the three investigated salts, $\mathrm{FeCl}_{3}$ makes the best choice for graphitization catalyst precursor to obtain uniformly graphitized mesoporous carbon xerogels. The obtained carbon samples were characterized by means of SEM, TEM, X-ray diffraction, Raman spectroscopy, $\mathrm{N}_{2}$ physisorption and thermogravimetric analysis.
\end{abstract}

Keywords. Organic xerogel; carbon xerogel; graphitization; mesoporosity; sol-gel synthesis.

\section{Introduction}

In the last few years, growing interest can be observed in methods of synthesizing 3D meso-, macroporous and/or hierarchically-structured porous carbon materials with graphitic framework, easily accessible nanopores, large surface areas and with the possibility of obtaining durable monoliths (Fuertes and Alvarez 2004; Yoon et al 2005; Su et al 2005a; Wang et al 2008; Yuan et al 2010; Zhai et al 2011). It is already proven that these carbons exhibit extraordinary performance as electrocatalyst supports and as electrode materials (e.g. for fuel cells, double-layer capacitors and lithium ion batteries) (Su et al 2005b; Wang et al 2007, 2008; Sevilla et al 2008a; Xia et al 2008; Shanahan et al 2008; Sheng and Wang 2008; Teng et al 2010). The performance improvement is explained by the large surface, specific porosity (short pores) and graphitic nature of their pore walls (Wang et al 2008). The presence of well-interconnected meso- and macro-pores allows reduced diffusional limitations often occurring in classical carbon-supported catalysts, while the graphitization of carbon materials improves their electrical conductivity and assure outstanding chemical persistence. Owing to their special properties, nanoporous graphitic carbon materials have also been applied in 'carbon-only' catalysis (where carbon itself is applied as a

*Author for correspondence (wkicinski@wat.edu.pl) catalyst and not as a catalyst support) (Liang et al 2009) and in biosensing (Lu et al 2009). In many of the above mentioned applications, nanoporous, graphitic carbons are superior to inherently non-porous carbon nanotubes-which are also not suitable for creating robust monoliths.

Even though impressive progress has recently been made in the field of nanoporous carbon materials with designed pore architecture and macroscopic features (Chuenchom et al 2012), it still remains a great challenge to prepare carbon materials that combine well-developed and defined nanoporosity, high specific surface area and a high degree of graphitization. Graphitization of ordered porous carbon materials leads to significant distortion of pore order and shape and drastically reduced surface areas (Kruk et al 2007; Gao et al 2011). In addition, the range of graphitizable carbon precursors is limited and their graphitization demands high temperatures (above $2000{ }^{\circ} \mathrm{C}$ (Yoon et al 2005)). On the other hand, in many electrochemical applications, perfect porous arrangement and very high pore uniformity are not always necessary (Rolison 2003), yet a controlled architecture and the presence of meso- and macro-pores with some quantity of micro-pores (hierarchical porosity) can be very useful in terms of buffering, transporting and confining electrolyte ions (Wang et al 2008).

In order to bypass the problematic high temperature graphitization and the graphitizable carbon precursors limitation, most of the latest approaches for production of 
nanoporous graphitized carbons employ in situ generated transition metal nanoparticles (Lu et al 2006; Sevilla et al 2007, 2008b; Sevilla and Fuertes 2009; Long et al 2010). These are fulfilling the two tasks: they act as a template for the nanoporosity and simultaneously induce graphitization (Wang et al 2007; Xia et al 2008; Sheng and Wang 2008; Teng et al 2010). The main advantage of the so-called catalytic graphitization is that it occurs at relatively low temperatures (Lu et al 2006). Catalytic graphitization has also often been combined with hard (Lee et al 2009) and soft templating (Gao et al 2011) routes to enhance the nanoporosity of carbon.

Out of the range of potential porous graphitic carbon precursors, carbon xerogels (CXs) seem to be an interesting choice, for at least three reasons: (i) their easily-tailored, consistently reproduced internal morphology (nanostructure of the primary particle morphology and pore texture), (ii) their 3D continuous hiererchical architecture and (iii) the possibility of designing the external morphology in suitable forms (especially monoliths, but also thin films, fibers or powders) for practical applications. Carbon xerogels are micromacroporous or micro-mesoporous materials with disordered pore system prepared by simple evaporative drying and pyrolysis of organic gels (Job et al 2006). Microporosity is developed during the carbonization step whilst mesoand macro-porosity is developed from phase separation and is easily controllable by varying synthesis conditions. As a result, there is no need for any templating. Since carbon gels are non-graphitizing materials, they need to be doped with a graphitization catalyst in order to convert them from amorphous to graphitic materials (Han et al 2003; Hyeon et al 2003; Fu et al 2005; Jin et al 2010; Wang et al 2011; Hasegawa et al 2012; Qi et al 2012).

Taking into account that the performance of carbon materials in specific applications is determined by their structural features such as pore diameter, hierarchical porous architectures, surface character and graphitization degree, structure tailored-carbon xerogels became attractive materials as versatile graphitic carbon precursors. As meso-macroporous and open pore network materials, partially graphitized carbon xerogels seem to be promising candidates for liquid phase applications, since the presence of large amounts of nanopores allows minimizing diffusion limitations in the carbon matrix.

In this paper, carbon xerogels with tailored porosity and graphitic structures have been synthesized by using sol-gel polymerization of resorcinol and furfural carried out in a water/methanol solution of transition metal chlorides. The influence of the water/methanol mass ratio in the starting solution, of the graphitization catalyst precursor's type and amount and of the pyrolysis temperature on the xerogels' structural properties were investigated.

\section{Experimental}

The experimental data of the synthesis of organic xerogel (OX) materials is shown in table 1 . The synthesis is described as follows: resorcinol and an inorganic salt were dissolved in a water/methanol mixture and furfural was added. The molar ratio of furfural to resorcinol was held at a constant value of 2.3 while the water/methanol $\left(\mathrm{H}_{2} \mathrm{O} / \mathrm{MeOH}\right)$ mass ratio and the metal chloride $\left(\mathrm{MCl}_{x}\right)$ content were constantly varied (table 1). Methanol has two functions: it acts as a co-solvent to increase the solubility of furfural, whilst the amount of methanol also affects the structure and morphology of the organic and carbon xerogel (CX) by delaying phase separation.

With the exception of mixtures with $\mathrm{FeCl}_{3}$ (which very easily hydrolyzes and results in acidic solution), sol-gel polymerization was initiated using concentrated hydrochloric acid $(37 \mathrm{wt} \%, 0.8 \mathrm{wt} \%$ of the starting mixtures with $\mathrm{CoCl}_{2}$ and $\mathrm{NiCl}_{2} \cdot 6 \mathrm{H}_{2} \mathrm{O}$ ). A few mixtures were prepared with the addition of methanol-stabilized commercial silica sol Ludox 40 (40 wt\% $\mathrm{SiO}_{2}$ water solution, silica particles of $24 \mathrm{~nm}$ in diameter). In those cases, silica sol was at first dispersed in methanol, and then the following substrates were added. Water was not added since it was introduced with silica sol.

The resulting mixtures were vigorously stirred and sealed in a beaker. Sol-gel polymerization was carried out by holding the mixtures at $60{ }^{\circ} \mathrm{C}$. Rigid resorcinol-furfural $(\mathrm{R}-\mathrm{F})$ aqua-alcogels saturated with metal chlorides $\left(\mathrm{R}-\mathrm{F} / \mathrm{MCl}_{x}\right)$ were obtained within a few minutes. The gels were aged for 1 day at $60{ }^{\circ} \mathrm{C}$, then dried under a perforated foil for 3 days at $60{ }^{\circ} \mathrm{C}$, and finally without any confinement at $100{ }^{\circ} \mathrm{C}$ for a few more days. During drying, the gels shrank. As a result monolithic organic xerogels impregnated with metal chlorides $\left(\mathrm{OX} / \mathrm{MCl}_{x}\right)$ were obtained (with a retained shape of the beaker).

Carbonization at 800 or $1050{ }^{\circ} \mathrm{C}$ for $2 \mathrm{~h}$ with heating rate of $5{ }^{\circ} \mathrm{C} / \mathrm{min}$ under flow of pure $\mathrm{N}_{2}$ leads to solids with magnetic properties, revealed by the attraction of xerogels to a magnet. In each case, pyrolysis at $800{ }^{\circ} \mathrm{C}$ causes at least a partial reduction of metal chlorides to their metallic state. After carbonization, metals constituted up to $39 \mathrm{wt} \%$ of $\mathrm{CX} /$ metal composites. The obtained samples were immersed in an excess amount of concentrated $\mathrm{HCl}$ for $24 \mathrm{~h}$. Samples with $\mathrm{SiO}_{2}$ were treated with $15 \% \mathrm{HF}$. That purification procedure leads to the removal of metallic particles and complete loss of the CXs' magnetic properties. Some chosen $\mathrm{MCl}_{x}$-doped organic xerogels were washed in water before carbonization in order to check if it is possible to completely remove the metal ions from the R-F network by water purification.

The obtained organic and carbon xerogels are referred to in the paper as OX-, CX-x-y-z, where $x$ refers to the sample number, $y$ and $z$ describe the treatments of OXs or CXs - temperature of carbonization $\left(800,1050{ }^{\circ} \mathrm{C}\right.$ ) and washing with $\mathrm{HCl}$, $\mathrm{HF}$ or $\mathrm{H}_{2} \mathrm{O}$. Selected samples were investigated by means of the following techniques: scanning electron microscopy (SEM)_LEO 1530, transmission electron microscopy (TEM) - Tecnai F30 and powder X-ray diffraction (XRD)-Siemens D500 powder diffractometer with $\mathrm{CuK} \alpha$ radiation. The $\mathrm{N}_{2}$ physisorption experiments were 
Table 1. Organic xerogel recipes and content of metal in carbon xerogel/metal composite obtained after carbonization.

\begin{tabular}{|c|c|c|c|}
\hline Sample & $\mathrm{R} / \mathrm{F} / \mathrm{W} / \mathrm{M} / \mathrm{MCl}_{x} / \mathrm{SiO}_{2}^{\mathrm{A}}[\mathrm{g}]$ & $\begin{array}{l}\text { Mechanical integrity } \\
\text { and drying shrink of } \\
\text { organic xerogels }\end{array}$ & $\begin{array}{l}\text { Metal content (wt.\%) in } \\
\text { carbon xerogel }^{\mathrm{D}}\end{array}$ \\
\hline OX-1 & $7 \cdot 5 / 15 / 70 / 71 / 25 \mathrm{FeCl}_{3}$ & B & 30 \\
\hline OX-2 & $7 \cdot 5 / 15 / 70 / 71 / 12 \mathrm{FeCl}_{3}$ & B & 26 \\
\hline OX-3 & $7 \cdot 5 / 15 / 70 / 55 \cdot 5 / 25 \mathrm{FeCl}_{3}$ & $\mathrm{~B}-\mathrm{C}$ & 35 \\
\hline OX-4 & $7 \cdot 5 / 15 / 70 / 31 \cdot 5 / 12 \mathrm{FeCl}_{3}$ & $\mathrm{C}$ & 31 \\
\hline OX-5 & $7 \cdot 5 / 15 / 70 / 63 / 20 \mathrm{FeCl}_{3}$ & B & 29 \\
\hline OX-6 & $7 \cdot 5 / 15 / 110 / 47 \cdot 5 / 40 \mathrm{FeCl}_{3}$ & $\mathrm{C}$ & 38 \\
\hline OX-7 & $7 \cdot 5 / 15 / 70 / 71 / 35 \mathrm{NiCl}_{2} \cdot 6 \mathrm{H}_{2} \mathrm{O}$ & B & 36 \\
\hline OX-8 & $7 \cdot 5 / 15 / 90 / 63 / 60 \mathrm{NiCl}_{2} \cdot 6 \mathrm{H}_{2} \mathrm{O}$ & B & 39 \\
\hline OX-9 & $7 \cdot 5 / 15 / 65 / 31 \cdot 5 / 18 \mathrm{NiCl}_{2} \cdot 6 \mathrm{H}_{2} \mathrm{O}$ & $\mathrm{C}$ & 28 \\
\hline OX-10 & $7 \cdot 5 / 15 / 70 / 71 / 20 \mathrm{CoCl}_{2}$ & B & 27 \\
\hline OX-11 & $7 \cdot 5 / 15 / 70 / 63 / 20 \mathrm{CoCl}_{2}$ & B & 26 \\
\hline OX-12 & $7 \cdot 5 / 15 / 80 / 63 / 40 \mathrm{CoCl}_{2}$ & B & 36 \\
\hline OX-13 & $7 \cdot 5 / 15 / 70 / 47 \cdot 5 / 15 \mathrm{CoCl}_{2}$ & $\mathrm{C}$ & 29 \\
\hline OX-14 & $7 \cdot 5 / 15 / 70 / 31 \cdot 5 / 10 \mathrm{CoCl}_{2}$ & $\mathrm{C}$ & 25 \\
\hline OX-15 & $7 \cdot 5 / 15 / 0 / 71 / 12 \mathrm{FeCl}_{3} / 116,5 \mathrm{SiO}_{2} \mathrm{sOL}$ & $\mathrm{B}-\mathrm{C}$ & 9 \\
\hline OX-16 & $7 \cdot 5 / 15 / 0 / 95 / 20 \mathrm{FeCl}_{3} / 90 \mathrm{SiO}_{2} \mathrm{sOL}$ & B & 11 \\
\hline OX-17 & $7 \cdot 5 / 15 / 0 / 71 / 25 \mathrm{FeCl}_{3} / 100 \mathrm{SiO}_{2} \mathrm{sOL}$ & B & 12 \\
\hline OX-18 & $7 \cdot 5 / 15 / 0 / 79 / 15 \mathrm{CoCl}_{2} / 100 \mathrm{SiO}_{2} \mathrm{sOL}$ & B & 6 \\
\hline OX-19 & $7 \cdot 5 / 15 / 0 / 111 / 20 \mathrm{NiCl}_{2} \cdot 6 \mathrm{H}_{2} \mathrm{O} / 70 \mathrm{SiO}_{2} \mathrm{SOL}$ & B & 6 \\
\hline
\end{tabular}

$\mathrm{OX}=$ organic xerogel, ${ }^{\mathrm{A}} \mathrm{R}$ resorcinol, $\mathrm{F}$ furfural, W water, $\mathrm{M}$ methanol, $\mathrm{MCl}_{x}$ metal chloride, $\mathrm{SiO}_{2}$ sol silica sol. ${ }^{\mathrm{B}}$ Enhanced mechanical integrity, substantial shrinkage, in some cases cracking during the drying. This occurs for samples synthesized at low $\mathrm{H}_{2} \mathrm{O} / \mathrm{MeOH}$ ratio. ${ }^{\mathrm{C}}$ Brittle, low shrinkage and no cracking during drying. This occurs for samples synthesized at high $\mathrm{H}_{2} \mathrm{O} / \mathrm{MeOH}$ ratio. ${ }^{\mathrm{B}-\mathrm{C}}$ Intermediate mechanical properties. ${ }^{\mathrm{D}}$ The metal content within the carbon matrix was calculated from the mass of xerogels after carbonization (carbon/metal composite) and after purification with $\mathrm{HCl} / \mathrm{HF}$ solution (pure carbonaceous material from which metals and $\mathrm{SiO}{ }_{2}$ were removed).

performed using volumetric adsorption equipment-the ASAP 2010 apparatus (Micromeritics) at $-196{ }^{\circ} \mathrm{C}$. The BET specific surface area $\left(S_{\mathrm{BET}}\right)$ was calculated from the nitrogen adsorption isotherm in the relative pressure range of 0.05$0 \cdot 25$. The total pore volume $\left(V_{\mathrm{t}}\right)$ was estimated from the volume adsorbed at a relative pressure of 0.99. Note that the $\mathrm{N}_{2}$ sorption technique is useful to investigate pores up to $100 \mathrm{~nm}$, thus $V_{\mathrm{t}}$ means the total volume of pores below c.a. $100 \mathrm{~nm}$ (not the total voids volume, which is the sum of the volume of micro-, meso- and large-macropores). The thermogravimetral profiles of the samples were recorded on a thermogravimetric analyzer (TGA) — Labsys TG, Setaramusing $\mathrm{O}_{2}(99.999 \%)$ as a carrier gas with a heating ramp of $10{ }^{\circ} \mathrm{C} / \mathrm{min}$. The Raman spectra were recorded with a dispersive Raman spectrometer with spectral resolution of $2 \mathrm{~cm}^{-1}$. The radiation source was a laser operating at a wavelength of $532 \mathrm{~nm}$.

\section{Results and discussion}

\subsection{Morphology_SEM observations}

As seen in the SEM micrographs (figures 1 and 2), the carbon xerogel network differs significantly in particle size and shape depending on the condensation conditions (please note the different magnification of the images). Their size ranges widely: from c.a. $6 \mu \mathrm{m}$ (figure 1) to c.a. $50 \mathrm{~nm}$ (figure 2). Open-celled, macroporous and colloidal structures were obtained for high $\mathrm{H}_{2} \mathrm{O} / \mathrm{MeOH}$ ratios and/or high salt contents in the starting mixtures. In contrast, nanosized structures were obtained from starting mixtures with low $\mathrm{H}_{2} \mathrm{O} / \mathrm{MeOH}$ ratios and/or low salt content. These conditions enhance smaller and better connected gel particles, which create a continuous 3D mesoporous structure, i.e. CX-11 and CX12 (online resource figure S1, S2). Detailed research results concerning the influence of solvents ratio and salt content on the morphology of organic and carbon xerogels have been presented elsewhere (Kiciński et al 2011; Hasegawa et al 2012).

The magnified SEM image of macroporous colloidal xerogels reveals that if the metal is not removed from the carbonized sample, it can be observed on the carbon spheres. The surface of sample CX-9 (figure 1) has lumps adhering to the surface, which are most likely the Ni particles. In contrast, the surface of the spherules of colloidal CX-4 (figure 1) is clean and smooth if the metal salt is removed by water purification before carbonization.

Samples obtained with added silica sol exhibit a few micrometer voids which originate from the removal of $\mathrm{SiO}_{2}$. 

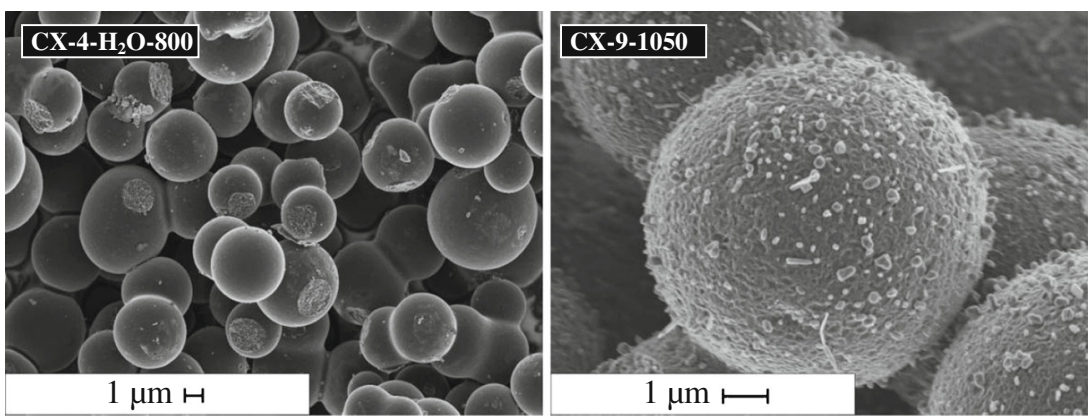

Figure 1. SEM images of carbon xerogels derived from mixtures with very low methanol content (colloidal xerogels).
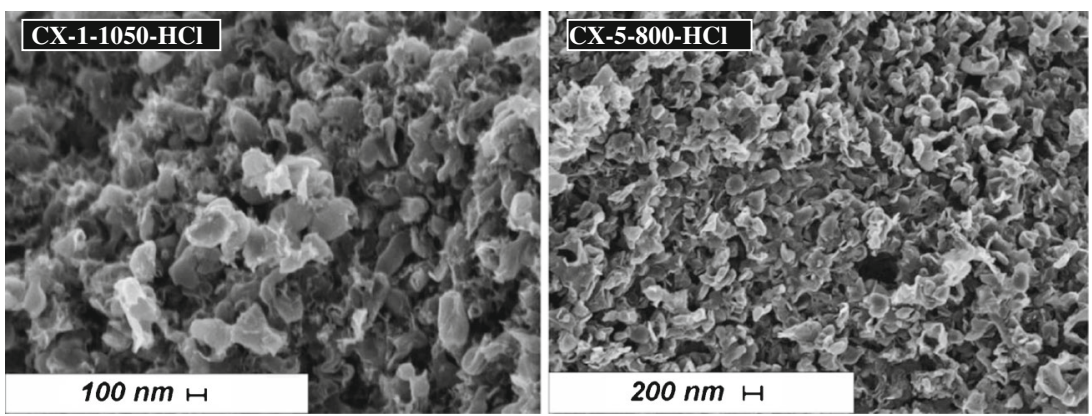

Figure 2. SEM images of carbon xerogels derived from mixtures with high methanol content (nanoflakes morphology).

That suggests that silica nanoparticles coagulated into larger, micrometric clusters in the starting mixture because of the presence of inorganic salts. As a result, CX-19-1050-HF possesses a hierarchical structure with porosity on multiple length scales - consisting of large voids (c.a. $1 \mu \mathrm{m}$, marked on figure 3 by rings) within the tightly-packed nanosized particles confining mesoporous space. Similar morphology is exhibited by CX-16-800-HF and CX-17-800-HF (online resource, figure S3). Since all $\mathrm{SiO}_{2}$-enriched xerogels were obtained from mixtures with a high content of $\mathrm{MeOH}$, they possess a polymeric-like structure built of nanosized particles. As a result of the removal of micron-sized $\mathrm{SiO}_{2}$ clusters, hierarchical structured xerogels can be obtained.

As observed, the gel network can be easily manipulated in the micro- and nano-scale by controlling the water/methanol ratio and inorganic salt concentration in the precursor mixture. Increasing the $\mathrm{H}_{2} \mathrm{O} / \mathrm{MeOH}$ ratio leads to the colloidal samples predominantly containing large macropores (resulting in low drying shrinkage and low density), while gradually decreasing the $\mathrm{H}_{2} \mathrm{O} / \mathrm{MeOH}$ ratio results in smaller pores and particles. The nano-networks of CXs without large macropores collapse to some extent during ambient pressure drying, as a result, these samples possess higher density.

\subsection{Structure-TEM, XRD, Raman spectra and TG}

Transmission electron microscopy results showed that during pyrolysis of metal chloride-doped OXs, a range of graphitic carbon nanostructures, i.e. ribbons and capsules, are created (figure 4). The carbon graphitic structures consist of long, randomly bent and entangled nano-ribbons (tens of microns in length and c.a. $10 \mathrm{~nm}$ in width). In particular, pyrolysis of $\mathrm{FeCl}_{3}$-doped samples results in a large amount of kinked, intertwined graphitic ribbons with a small amount of carbon in its amorphous phase.

As suggested in previous articles (Han et al 2003; Hyeon et al 2003; Fu et al 2005), the different curvatures of the ribbons and their round shape is caused by the shape of the metallic particles generated due to carbothermal reduction of metallic salts during pyrolysis. When samples are treated at $1050{ }^{\circ} \mathrm{C}, 10 \mathrm{~nm}$ thick graphitic ribbons wrapped around the particles can be observed (figure 5). Catalyst particles form the core for the formation of external multiwalled graphite shells, so that they indeed act as a matrix for the graphitic structures of carbon xerogels. The carbon nano-structures have high crystallinity, as demonstrated by the HRTEM microscopy images (figures 4 and 5), which display well-defined lattice fringes (002). Besides widespread nano-ribbons and nano-capsules, also tubular structures were observed for $\mathrm{NiCl}_{2}$-doped xerogels (online resource figure S4). Interestingly, similar tubular structures for $\mathrm{Ni}$ doped xerogels were also reported recently (Liu et al 2012b). Graphite structures initiate growth from the metallic particles (graphite structures) and then grow into the porous space of the xerogel matrix. In consequence, the material obtained after the heat treatment is made up of metal nanoparticles 

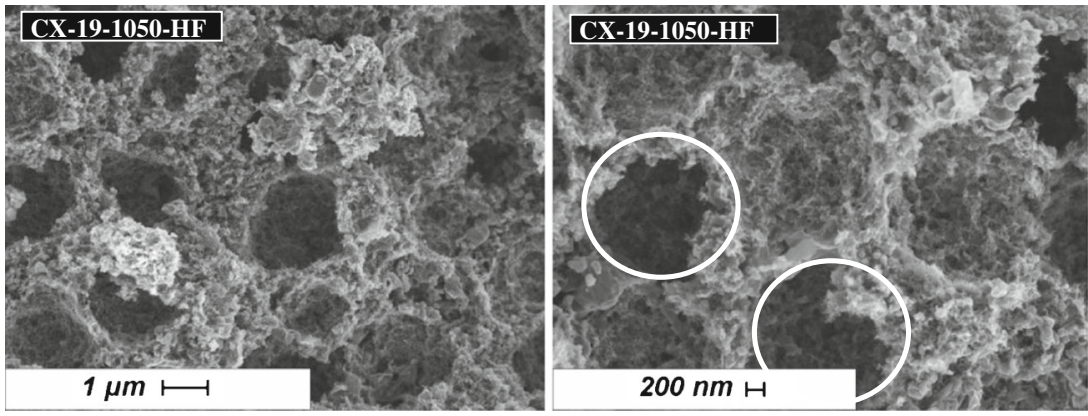

Figure 3. SEM images of carbon xerogel derived from mixtures with $\mathrm{SiO}_{2}$. CX19-1050-HF possesses large voids (indicated by circles) due to removal of $\mathrm{SiO}_{2}$ micrometer-sized clusters.
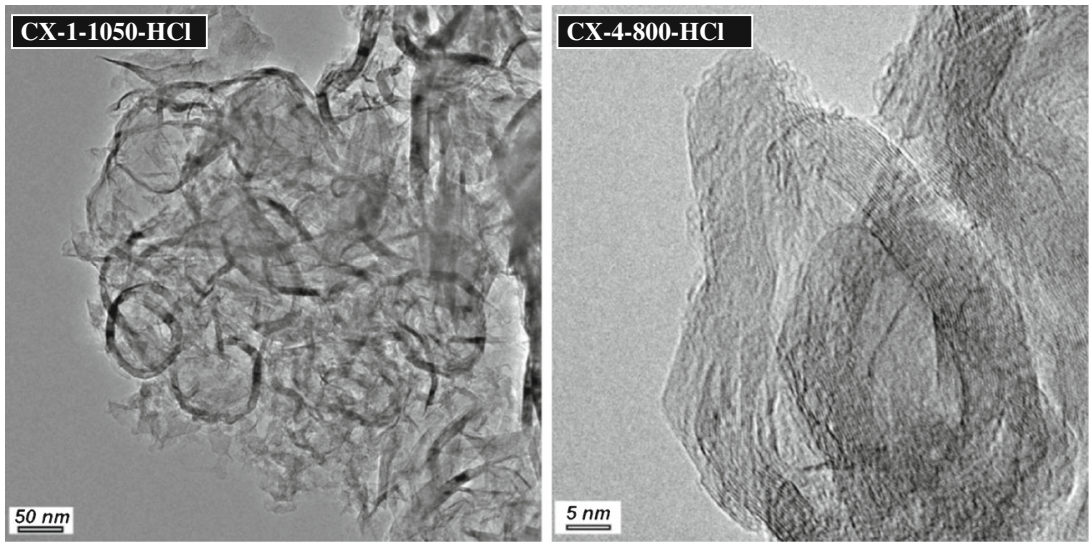

Figure 4. TEM micrograph of $\mathrm{CX}-1-1050-\mathrm{HCl}$ derived from mixture with $\mathrm{FeCl}_{3}$. Structure constitutes a bundle of entangled graphitic nanoribbons. Also empty graphitic nanocapsules were observed for carbons derived from $\mathrm{FeCl}_{3}$-doped mixtures $(\mathrm{CX}-4-$ $800-\mathrm{HCl})$.

dispersed throughout the carbonaceous matrix, which consists of a mixture of graphitic and amorphous carbon. The amorphous carbon constitutes a matrix binding the various graphitic structures all together. The carbon matrix distant from the metal particles retains its amorphous structure, which is especially visible for carbon xerogels obtained from $\mathrm{CoCl}_{2}$-doped samples (online resource figure $\mathrm{S} 4$ ). In contrast to Co-doped xerogels, for the Fe-doped carbons, graphitic nanoribbons are found to be ubiquitous.

Figures 6-8 show XRD spectra for the materials prepared at 800 or $1050{ }^{\circ} \mathrm{C}$. The XRD patterns of the Fecontaining CXs are shown in figure 6. Narrow and intense reflection related to $\mathrm{Fe}$ can be observed, suggesting formation of well-crystallized metallic particles during the high temperature treatment. During carbonization, the iron precursor was not only reduced, but also partially carburized, giving rise to a well-crystallized iron carbide phase. As noticed previously, the high, homogenous dispersion of the catalyst in the carbon matrix is crucial for obtaining high graphitic carbon yields and uniform, effective carbon graphitization (Han et al 2003; Fu et al 2005). On the other hand, in much research, even very fine (molecular) dispersion of transition metals in carbon precursors does not prevent sintering at higher temperatures $\left(>800^{\circ} \mathrm{C}\right)(\mathrm{Lu}$ et al 2006). As the temperature increases from 800 to $1050{ }^{\circ} \mathrm{C}$, the diffraction lines of $\mathrm{Fe}$ became much more pronounced due to thermally driven sintering (figure 6). Larger metal particles generate larger graphitic nanostructures (i.e. larger capsules with thicker walls) which in turn lead to graphitic carbons with reduced mesoporosity (Xia et al 2008). As stated elsewhere, the thinner the walls of the graphitic nano-ribbons, the more enhanced the mosoporosity of graphitized carbon materials (Sheng and Wang 2008).

The X-ray diffraction patterns of the CXs after metal and silica removal confirm the structural graphitic order of these materials (figures 7 and 8). The XRD patterns exhibit intense reflections at $2 \theta=26,43$ and $54^{\circ}$ which correspond to the (002), (100/101) and (004) diffractions of the graphitic framework, respectively. The (002) and (004) peaks reflect the length of the $c$-axis (perpendicular to the basal plane), in other words the thinner the graphite sheets, the broader and less intense the (002) and (004) diffraction peaks are. The presence of the clear (004) diffraction peak for $\mathrm{CX}-3-1050-\mathrm{HCl}$ (figure 7), CX-7-1050-HCl (figure S5 


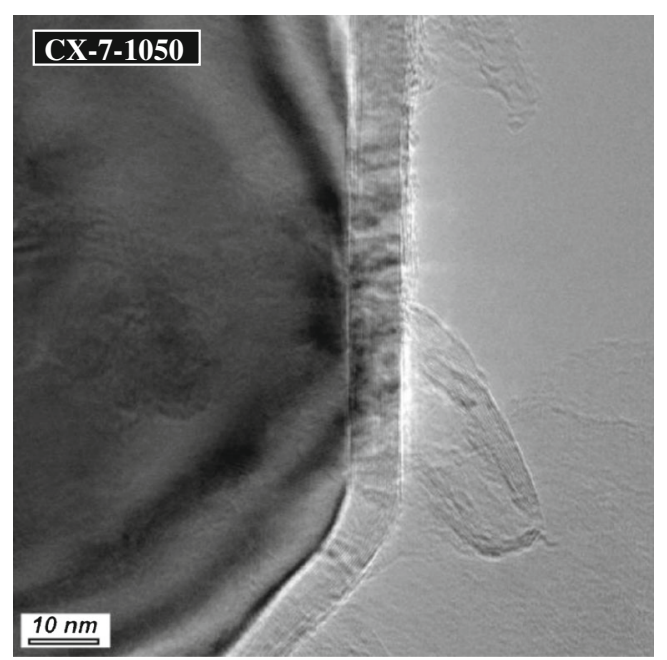

Figure 5. TEM micrograph of Ni-doped xerogel, CX-7-1050.

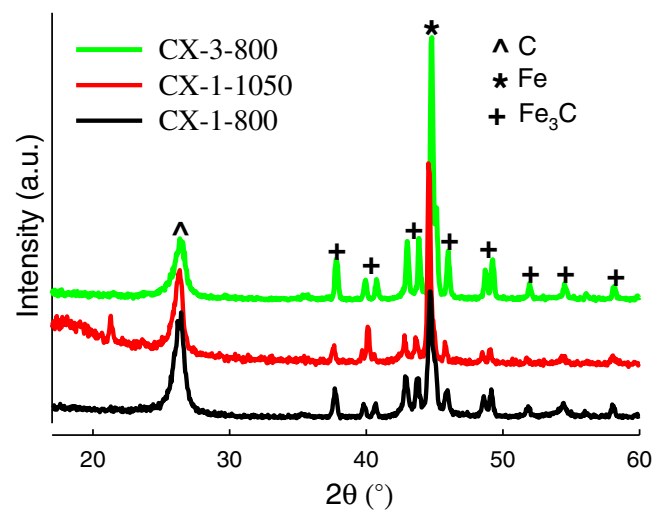

Figure 6. XRD patterns of $\mathrm{FeCl}_{3}$-doped xerogels carbonized at different temperatures. Well defined metallic and graphitic phases are distinguished.

online resource) and CX-19-1050-HF (figure 8) suggests the existence of well-graphitized areas with three-dimensional stacking order.

The plane spacing, $d_{002}$, and the crystallite sizes perpendicular to the basal plane $L_{\mathrm{c}}$ were deduced by applying Scherrer's equation to the (002) diffraction peak. They are listed in table 2. Except for CX-2- $\mathrm{H}_{2} \mathrm{O}-800$ (discussed below) the $d_{002}$ values range from 0.336 to $0.340 \mathrm{~nm}$, and the $L_{\mathrm{c}}$ values from 7.8 to $14.1 \mathrm{~nm}$. Variation in the temperature of treatment from 800 to $1050{ }^{\circ} \mathrm{C}$ does not induce a significant increase in the structural order. This suggests that while the increase in temperature does not have a large influence on the degree of structural order of the created graphitic carbon, it may still affect the amount of graphitic structures. All the values obtained for $d_{002}$ are larger than the value corresponding to HOPG $(0.335 \mathrm{~nm})$, suggesting that various distortions occur in the stacking of the graphene layers (turbostratic carbon).

The XRD patterns corresponding to the samples obtained from $\mathrm{CoCl}_{2}$-doped xerogels (CX-12, figure 7, CX-13 and

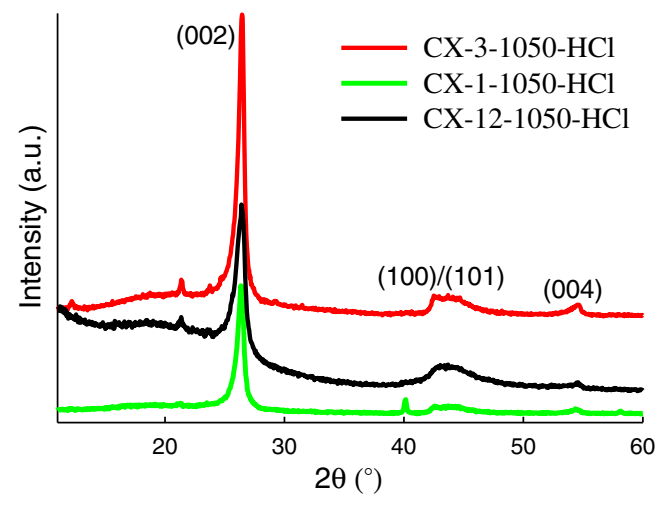

Figure 7. XRD patterns of $\mathrm{HCl}$ treated $\mathrm{CXs}$ obtained from $\mathrm{FeCl}_{3}$ and $\mathrm{CoCl}_{2}$-doped xerogels.

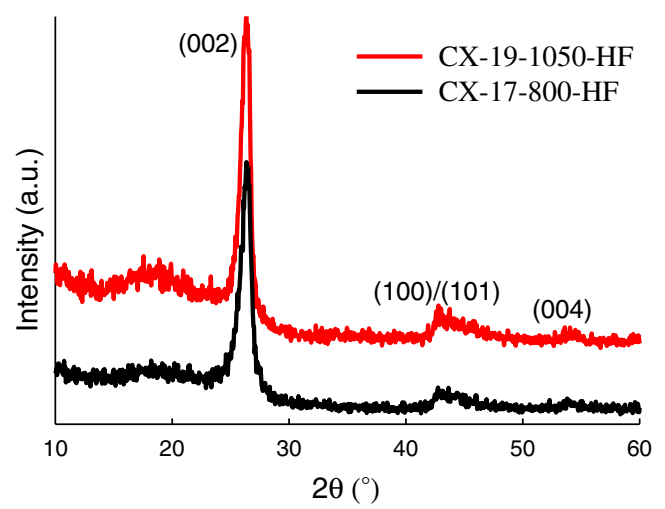

Figure 8. $\mathrm{CXs}$ derived from $\mathrm{NiCl}_{2}$ - and $\mathrm{FeCl}_{3}$-doped organic xerogels with added $\mathrm{SiO}_{2}$ carbonized at different temperatures.

CX-10, figures S6, S7 online resource) demonstrate the formation of graphitic carbon ( 002 reflection at $2 \theta \sim 26^{\circ}$ ), but the main XRD peaks for these samples appeared to be a superposition of a less intense broader peak and a narrow peak centered at $26^{\circ}$. In particular, the XRD patterns for CX13 suggest that this material consists of a large amount of poorly organized carbon with small quantities of graphitised carbon embedded in its structure. This would suggest that minor parts of the sample are well graphitized, while major parts of the samples are graphitic to a much smaller extent. This hypothesis is consistent with TEM observations for $\mathrm{CoCl}_{2}$-doped xerogels-the xerogel samples consisted of a mixture of amorphous carbon and graphitic structures (figure S4). The high intensity of the (002) diffraction for CX-12$1050-\mathrm{HCl}$ is due to the very high $\mathrm{CoCl}_{2}$ content and high carbonization temperature $\left(1050^{\circ} \mathrm{C}\right)$, while the carbonization of samples with lower content of $\mathrm{CoCl}_{2}$ at $800{ }^{\circ} \mathrm{C}$ yields poorly graphitized material (CX-10-800-HCl, figure S7). Comparing these samples with $\mathrm{FeCl}_{3}$ - and $\mathrm{NiCl}_{2}$-doped xerogels, $\mathrm{CoCl}_{2}$ seems to be less effective precursor of the graphitization catalyst. That is probably due to the relative thermal stability of $\mathrm{CoCl}_{2}$ (table 3 ). 
Table 2. Structural and textural properties of the chosen carbon xerogels.

\begin{tabular}{|c|c|c|c|c|}
\hline Sample & $d_{002}(\mathrm{~nm})$ & $L_{\mathrm{c}}(002)(\mathrm{nm})$ & $S_{\mathrm{BET}}\left(\mathrm{m}^{2} / \mathrm{g}\right)$ & $V_{\mathrm{t}}\left(\mathrm{cm}^{3} / \mathrm{g}\right)$ \\
\hline CX-1-800 & $0 \cdot 338$ & 10 & - & - \\
\hline $\mathrm{CX}-1-800-\mathrm{HCl}$ & - & - & 234 & 0.76 \\
\hline CX-1-1050 & $0 \cdot 338$ & $12 \cdot 1$ & - & - \\
\hline $\mathrm{CX}-1-1050-\mathrm{HCl}$ & $0 \cdot 338$ & 14 & - & - \\
\hline $\mathrm{CX}-2-800-\mathrm{HCl}$ & - & - & 189 & $0 \cdot 68$ \\
\hline $\mathrm{CX}-2-\mathrm{H}_{2} \mathrm{O}-800$ & $0 \cdot 341$ & 6 & - & - \\
\hline $\mathrm{CX}-3-1050-\mathrm{HCl}$ & $0 \cdot 337$ & $14 \cdot 2$ & 188 & 0.32 \\
\hline CX-3-800 & $0 \cdot 340$ & $9 \cdot 1$ & - & - \\
\hline $\mathrm{CX}-3-800-\mathrm{HCl}$ & - & - & 340 & 0.43 \\
\hline $\mathrm{CX}-7-1050-\mathrm{HCl}$ & $0 \cdot 336$ & $14 \cdot 1$ & 171 & $0 \cdot 38$ \\
\hline CX-10-800-HCl & $0 \cdot 340$ & $7 \cdot 8$ & - & - \\
\hline $\mathrm{CX}-12-1050-\mathrm{HCl}$ & $0 \cdot 339$ & 8 & 585 & 0.52 \\
\hline CX-13-1050-HCl & $0 \cdot 339$ & $7 \cdot 2$ & - & - \\
\hline CX-15-800-HF & - & - & 396 & 0.41 \\
\hline CX-17-800-HF & $0 \cdot 337$ & $8 \cdot 2$ & 296 & 0.60 \\
\hline CX-19-1050-HF & $0 \cdot 338$ & 8.9 & 268 & 0.72 \\
\hline
\end{tabular}

Table 3. Thermal stability of Fe(III), Co(II), and Ni(II)-chlorides.

\begin{tabular}{lcc}
\hline Metal chloride & Melting point $\left({ }^{\circ} \mathrm{C}\right)$ & Boiling point $\left({ }^{\circ} \mathrm{C}\right)$ \\
\hline $\mathrm{FeCl}_{3}$ & 306 & 315 decomposition \\
$\mathrm{NiCl}_{2}$ & - & 973 sublimation \\
$\mathrm{CoCl}_{2}$ & 724 & 1049 \\
\hline
\end{tabular}

Interestingly, we found out that $\mathrm{Fe}$ cannot be completely removed from $\mathrm{FeCl}_{3}$-doped organic xerogel by multiple boiling in excess distilled water. The XRD pattern of a very well purified organic xerogel $\left(\mathrm{OX}-2-\mathrm{H}_{2} \mathrm{O}\right.$, figure $\left.\mathrm{S} 7\right)$ proves that no crystalline forms of iron or its compounds exist in the organic xerogel matrix. Yet, after pyrolysis of this sample at $800{ }^{\circ} \mathrm{C}\left(\mathrm{CX}-2-\mathrm{H}_{2} \mathrm{O}-800\right.$, figure $\left.\mathrm{S} 7\right)$ crystalline forms of iron $\left(\mathrm{Fe}, \mathrm{Fe}_{3} \mathrm{C}, \mathrm{Fe}_{2} \mathrm{O}_{3}\right)$ and carbon are detected in the created CX. Carbonization produces sample exhibiting clear attraction to a magnet. This suggests that iron, probably in its ionic state, can permanently bond with the resorcinolfurfural matrix. That is most likely caused by the resorcinol, which is a complexing agent towards $\mathrm{Fe}^{3+}$ ions, and/or by the abundant oxygen functional groups present in the R-F xerogel, or by the chelation of the polymeric matrix by the phenolic groups (Moreno-Castilla et al 2003). In contrast, water purified and carbonized samples derived from the $\mathrm{NiCl}_{2}$ - and $\mathrm{CoCl}_{2}$-doped OXs did not exhibit attraction to a magnet. Complexed iron ions can not be effectively removed from the gel framework by washing with water (Kiciński et al 2011). This phenomenon can be responsible for the more uniform graphitization of xerogels doped with $\mathrm{FeCl}_{3}$ than with other chlorides.

On the basis of the TEM and XRD analyses, it can be concluded that during the pyrolysis of the resorcinol-furfural xerogels impregnated with metallic chlorides, the following processes take place: carbonization of the R-F xerogel and its transformation into amorphous carbon; a carbothermal reduction of metal chlorides to metallic particles; and finally, a catalytically induced solid-state transformation of the surrounding amorphous carbon framework into graphitic nanostructures. Transition metal nanoparticles act as graphitization catalysts according to a dissolution-precipitation mechanism (Oya and Marsh 1982). During high temperature treatment, the metallic nanoparticles move through the amorphous carbon matrix, converting it into a graphitic one (see online resource, figure $\mathrm{S} 8$ for detailed discussion).

The structure of the carbon phase of the CXs obtained was also studied by Raman spectroscopy. The Raman spectra of carbon xerogels exhibit two characteristic signals (online resource, figure S9). One peak, at around $1360 \mathrm{~cm}^{-1}$, can be assigned to the disorder-induced line ( $\mathrm{D}$ band) of a carbon structure (related to imperfections in the graphitic $s p^{2}$ carbon structures). The second peak, at around $1580 \mathrm{~cm}^{-1}$, is the graphite line ( $\mathrm{G}$ band), which corresponds to the $E_{2 \mathrm{~g}}$ mode of hexagonal graphite and is related to the vibration of $s p^{2}$-hybridized carbon atoms in the graphite layer. In carbon samples derived from mixtures with $\mathrm{FeCl}_{3}$ and $\mathrm{NiCl}_{2}$ (i.e. CX-1, CX-7) the $\mathrm{G}$ band is noticeably sharper and more intense than the $\mathrm{D}$ band. Carbons derived from $\mathrm{CoCl}_{2}$-doped xerogels (CX-11, CX-12) exhibit much less pronounced $\mathrm{G}$ bands, indicating their lower overall graphitization. This 
is in good agreement with the XRD results and TEM studies indicating lower graphitization degree of $\mathrm{CoCl}_{2}$ doped xerogels.

Generally, owing to their crystallographic order, graphitic carbons are more stable against air oxidation than amorphous carbons. To study the oxidation resistance, TG analyses were performed for the carbon xerogels under pure oxygen. Depending on the graphitization catalyst precursor and its content, CXs exhibit significantly varied oxidation behaviour (online resource, figures S10 and S11). Carbon materials derived from $\mathrm{CoCl}_{2}$-doped xerogels are definitely the least stable against burning in pure $\mathrm{O}_{2}$ (CXs-12, -13 and -18). Carbon materials obtained from $\mathrm{FeCl}_{3}$-doped xerogels exhibit higher stability against oxidation (i.e. CX-3) than the one obtained from mixtures with $\mathrm{CoCl}_{2}$. Sample CX-19 (figure S10) exhibits two-leveled oxidation behaviour. The amorphous matrix probably starts to burn in temperatures above $450{ }^{\circ} \mathrm{C}$, while graphitic structures oxidize above $600{ }^{\circ} \mathrm{C}$. The TG analyses are consistent with the XRD and TEM results. Less graphitized xerogels (from $\mathrm{CoCl}_{2}$-doped organic gels) are more rapidly oxidized compared to the better graphitized samples.

\subsection{Texture $-\mathrm{N}_{2}$ physisorption}

Representative nitrogen sorption isotherms corresponding to the graphitized samples after the removal of metal particles are shown in figures 9 and 10 and figures S12, S13 (online resource). All of the samples exhibit adsorption isotherms of type IV (or isotherms being combination of types IV and II) and show pronounced hysteresis loops (H3), a feature that is associated with capillary condensation within mesopores (Rouquerol et al 1999). This is indicative of the presence of constrictions in the porous network, which are most likely associated with disordered carbon. The spreading of hysteresis loops in a very broad range of relative pressures $\left(p / p_{\circ}=0.45-0.99\right)$ suggests the existence of different pore sizes spanning from micro- to macro-pores. Aside from sample CX-3, the CXs possess almost vertical tails of adsorption branches at the $p / p_{\circ}$ near 1.0 (no distinctive plateau), which implies the presence of macroporosity and multilayer adsorption. In addition, the large nitrogen adsorption uptakes for relative pressures $>0.9$ are typical of nanosized materials, when adsorption for high relative pressures also occurs at the outer surface of the nanoparticles.

Carbon xerogels possess two types of pores: phase separation-derived voids between the xerogel particles (meso- and/or macro-pores) and pyrolysis-derived voids inside the xerogel particles (micropores). The total pore volume of CXs investigated is in the range of $0.3-0.75 \mathrm{~cm}^{3} / \mathrm{g}$, table 2. The porosity of the CXs consists partly of micropores $\left(\mathrm{N}_{2}\right.$ adsorption uptake for very low $p / p_{0}$, especially well developed for CX-12, figure 9), but mainly of framework-confined mesopores expanding into macropores. From $\mathrm{N}_{2}$ sorption analysis, one can conclude that CXs obtained from solutions with high methanol content contain pores with a wide range of sizes which cross the

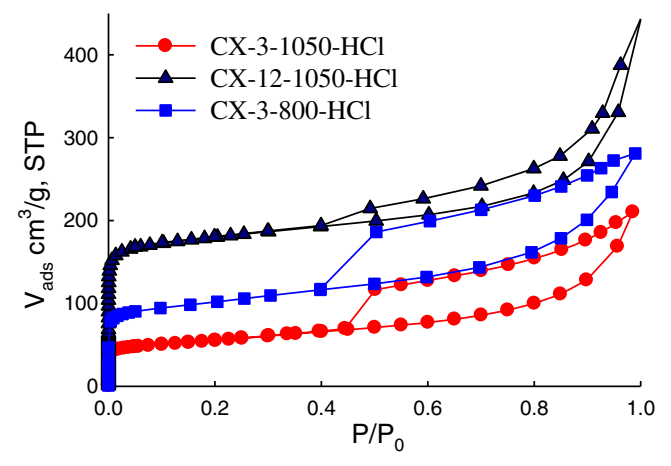

Figure 9. Nitrogen adsorption-desorption isotherms of colloidal CX-3 (obtained at two different pyrolysis temperatures) and CX-12 with well-developed microporosity.

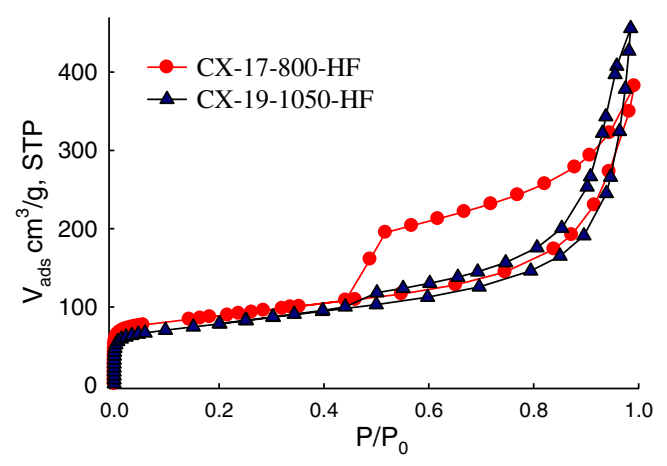

Figure 10. Nitrogen adsorption-desorption isotherms of carbon xerogels obtained from OXs impregnated with $\mathrm{SiO}_{2}$ colloidal particles. CX-19 exhibits a combination of type IV (capillary condensation) and type II (multilayer adsorption) isotherms.

micropore-mesopore boundary (CX-1, -2, figure S12, CX19, figure 10) and expand into macropores.

As can be observed in sample CX-3, an increase of the pyrolysis temperature results in reduced microporosity (figure 9). That indicates more complete graphitization, but at the expense of the specific surface area and the pore volume. During carbonization, metallic particles cause partial carbon crystallization, thus decreasing the microporosity of CXs and allowing them to develop mesoporosity. The surface homogeneity of carbon xerogels can be more precisely described by low-pressure nitrogen adsorption isotherms in the logarithmic scale (see online resources figure S14 for detailed description). The graphitization process transforms microporous and amorphous carbon into graphitic carbon, which leads to the removal of heterogeneous sites on the carbon surface and hence also to reduce adsorption capacity at low relative pressures-which is normally related to the high-energy sites present on the solid surface (Kruk et al 2007).

The BET specific surface areas and $V_{\mathrm{t}}$ are listed in table 2 . The high surface area of CX-12 $\left(585 \mathrm{~m}^{2} / \mathrm{g}\right)$ is associated with the very well-developed microporosity within the amorphous carbon. This result is in agreement with the XRD observation. It is also consistent with TEM inspections of 
Co-doped samples which showed coexistence of amorphous and graphitic structures within the carbon matrix (figure S4 online resource).

It can be assumed that changing the methanol content, salt formula and quantity in the starting mixture of precursors, as well as the pyrolysis temperature significantly affects the porous structure of CXs. These results are coherent with the morphology of the CXs observed by means of SEM and TEM inspections which showed differences between colloidal and nanosized-polymeric xerogel structures and coexistence of amorphous and graphitic structures, respectively. SEM pictures confirm the differences revealed by $\mathrm{N}_{2}$ sorption analysis between the porous structures of CXs derived from mixtures with high and low values of $\mathrm{H}_{2} \mathrm{O} / \mathrm{MeOH}$.

By considering the results of research presented herein, one can conclude that the structure of nanoporous graphitized carbons derived from organic xerogels is a bundle of intertwined, highly-kinked graphitic ribbons and related structures (capsules, tubes) with coexisting amorphous and microporous phase. The schematic structure of such nanoporous graphitized carbons is proposed in figure 11. Carbons with such precious features are desired for energy storage/conversion devices. For example, the performance of CXs for electric double-layer capacitors is proved to be highly associated with their nanostructure (Lu et al 2012). A well-balanced surface area ratio of micropores to mesopores is essential for efficient capacitors. Suitable pore sizes of the carbon electrodes are critical to facilitate the mass transfer of electrolyte within the pores for fast redox reactions. The hierarchical pore structure of CXs and their conductive matrix is also important for the performance of direct methanol fuel cells. As it was recently pointed out (Qi et al 2012), it still remains extremely difficult to combine high conductivity (graphitic structure) with high surface area and developed mesoporosity as required for carbon supports for electrocatalysis.

Carbon xerogels remain an attractive research topic. Recent results suggest that the diverse advantages of CXs can be boosted even more by heteroatom-doping, e.g. nitrogendoping (Liu et al 2012a). Such CXs are becoming a very promising non-precious metal catalyst for fuel cells.

\section{Conclusions}

Carbon xerogels with various porous systems, diverse graphitic structures and various degrees of graphitization were obtained through the solid-state pyrolysis of Fe(III), $\mathrm{Ni}(\mathrm{II}), \mathrm{Co}(\mathrm{II})$ chlorides-doped resorcinol-furfural xerogels. The study of the impact of the water/methanol ratio, the amount and type of transition metal chlorides and the addition of silica sol on the morphology, texture and graphitization of CXs was undertaken in order to obtain nanoporous graphitized carbons combining large surface areas with a high degree of graphitization.

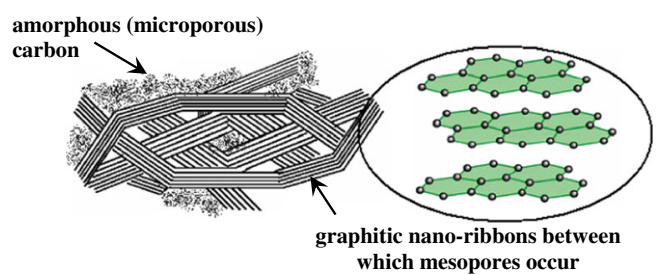

Figure 11. Nanoporous graphitic carbon is a crystalline material made of entangled graphitic ribbons occasionally covered by amorphous, microporous phase (biphasic carbon). Intertwined nature of porous graphitic carbon confers mechanical stability. Porous graphitic carbon is qualified as 'two-dimensional' graphite (turbostratic graphite). Sheet's curvature is induced by pentagonal and heptagonal rings presented in graphene sheets.

First, it was observed that the water/methanol ratio allows control of the final gel structure regardless of the inorganic salt concentration and type in the mixture of precursors. The lower the $\mathrm{H}_{2} \mathrm{O} / \mathrm{MeOH}$ ratio, the smaller the inter-granular pore size obtained-mesoporosity is enhanced and macroporosity is reduced. In contrast, low methanol content yields colloidal macroporous samples. If polymerization is carried out in the solution with a large amount of methanol, transition metal-doped carbon xerogels with a very high metal loading (up to $40 \mathrm{wt} \%$ ) can be obtained after carbonization.

Metallic nanoparticles act as an in situ created matrix for the graphitic carbon nanostructures. Unfortunately, the thermal-driven sintering increases the size of metal particles, which in turn results in large carbon nanostructures with thick graphitic walls. This may reduce the mesoporosity of the graphitic carbons obtained.

It could be concluded that all the carbon xerogels produced are to some extent biphasic materials, consisting of a mixture of amorphous and graphitic carbon. On the other hand, the ability of iron to bond to the xerogel matrix makes $\mathrm{FeCl}_{3}$ the best choice for uniform catalytic graphitization of carbon xerogels. On the basis of the performed analysis, one can conclude that the graphitization of CXs depends on the type and amount of the metal chloride used. The $\mathrm{CoCl}_{2}$-doped xerogels are the least graphitized ones. This effect is due to the different temperature and rate of melting, sublimation or decomposition of the different metal salts. Graphitization causes substantial reduction of microporosity and surface area, but the overall open and accessible porosity of carbon xerogels is still retained. Even though, conversion of amorphous carbon into graphitic carbon decreases microporosity, it results in enhanced mesoporosity. Macroporosity can be enhanced by addition of silica sol, which in the presence of inorganic salts coagulates into micrometric clusters.

\section{Acknowledgements}

This work was supported by the Ministry of Science and Education through the Department of Chemistry, Warsaw University under Grant IP2011006071. 


\section{Electronic Supplementary Material}

Supplementary material pertaining to this article is available on the Bulletin of Materials Science website (www.ias.ac.in/ matersci).

\section{References}

Chuenchom L, Kraehnert R and Smarsly B M 2012 Soft Matter 8 10801

Fu R, Baumann T F, Cronin S, Dresselhaus G, Dresselhaus M S and Satcher J H Jr 2005 Langmuir 212647

Fuertes A B and Alvarez S 2004 Carbon 423049

Gao W, Wan Y, Dou Y and Zhao D 2011 Adv. Energy Mater. 1115

Han S, Yun Y, Park K-W, Sung Y-E and Hyeon T 2003 Adv. Mater. 151922

Hasegawa G, Kanamori K and Nakanishi K 2012 Mater. Lett. 761

Hyeon T, Han S, Sung Y-E, Park K-W and Kim Y-W 2003 Angew. Chem. Int. Ed. 424352

Jin H, Zhanga H, Ma Y, Xu T, Zhong H and Wang M 2010 J. Power Sources 1956323

Job N, Sabatier F, Pirard J P, Crine M and Leonard A 2006 Carbon 442534

Kiciński W, Szala M and Nita M 2011 J. Sol-Gel Sci. Technol. 58 102

Kruk M, Kohlhaas K M, Dufour B, Celer E B, Jaroniec M, Matyjaszewski K, Ruoff R S and Kowalewski T 2007 Micropor. Mesopor. Mater. 102178

Lee T K, Ji X, Rault M and Nazar L F 2009 Angew. Chem. Int. Ed. 485661

Liang C, Xie H, Schwartz V, Howe J, Dai S and Overbury S H 2009 J. Am. Chem. Soc. 1317735

Long J W, Laskoski M, Keller T M, Pettigrew K A, Zimmerman T N, Qadri S B and Peterson G W 2010 Carbon 48501

Liu S, Zhang H, Xu Z, Zhong H and Jin H 2012a Int. J. Hydrogen Energy 3719065

Liu Z, Li J, Yang Y, Mi J H and Tan X L 2012b Mater. Res. Innovations 16(5) 362

Lu A-H, Li W-C, Salabas E-L, Spliethoff B and Schüth F 2006 Chem. Mater. 182086
Lu X, Xiao Y, Lei Z, Chen J, Zhang H, Ni Y and Zhang Q 2009 J. Mater. Chem. 194707

Lu X, Shen J, Ma H, Yan B, Li Z, Shi M and Ye M 2012 J. Power Sources 201340

Moreno-Castilla C, Maldonado-Hódar F J and Pérez-Cadenas A F 2003 Langmuir 195650

Oya A and Marsh H 1982 J. Mater. Sci. 17309

Qi J, Jiang L, Tang Q, Zhu S, Wang S, Yi B and Sun G 2012 Carbon 502824

Rolison D R 2003 Science 2991698

Rouquerol F, Rouquerol J and Sing K 1999 Adsorption by powders and porous solids. Principles, methodology and applications (San Diego, CA: Academic Press)

Sevilla M and Fuertes A B 2009 Mater. Chem. Phys. 113208

Sevilla M, Sanchís C, Valdés-Solís T, Morallón E and Fuertes A B 2007 J. Phys. Chem. C 1119749

Sevilla M, Salinas Martínez-de Lecea C, Valdés-Solís T, Morallón E and Fuertes A B 2008a Phys. Chem. Chem. Phys. 10 1433

Sevilla M, Sanchís C, Valdés-Solís T, Morallón E and Fuertes A B 2008b Carbon 46931

Shanahan P V, Xu L, Liang C, Waje M, Dai S and Yan Y S 2008 J. Power Sources 185423

Sheng Z M and Wang J N 2008 Adv. Mater. 201071

Su F, Zeng J, Bao X, Yu Y, Lee J Y and Zhao X S 2005a Chem. Mater. 173960

Su F, Zhao X S, Wang Y, Zeng J, Zhou Z and Yang Lee J 2005b J. Phys. Chem. B 10920200

Teng S J, Wang X X, Xia B Y and Wang J N 2010 J. Power Sources 1951065

Wang J N, Zhao Y Z and Niu J J 2007 J. Mater. Chem. 172251

Wang D-W, Li F, Liu M, Lu G Q and Cheng H-M 2008 Angew. Chem. 120379

Wang Z, Zhang X, Liu X, Lv M, Yang K and Meng J 2011 Carbon 49161

Xia B Y, Wang J N, Wang X X, Niu J J, Sheng Z M, Hu M R and Yu Q C 2008 Adv. Funct. Mater. 181790

Yoon S B, Chai G S, Kang S K, Yu J-S, Gierszal K P and Jaroniec M 2005 J. Am. Chem. Soc. 1274188

Yuan J, Giordano C and Antonietti M 2010 Chem. Mater. 225003

Zhai D, Du H, Li B, Zhu Y and Kang F 2011 Carbon 49725 